\title{
Decision making in elderly HCC
}

\author{
M A Trovato*, A Pesce, R Scilletta, A Branca, F Mosca, S Puleo \\ From XXIII Annual Meeting of the Italian Society of Geriatric Surgery \\ Lecce, Italy. 2-4 December 2010
}

\section{Background}

The decision making process in hepato-cellular carcinoma (HCC) relies on multiple factors. Hepatic surgery, in fact, has to take into consideration a patient's general medical condition, performance status, underlying liver disease, functional hepatic reserve. All these factors affect hepatic metabolism, flux and regeneration mechanism conditioning future liver remnant volume. What is more, hepatic regeneration is delayed, even if not completely impaired, in the elderly. Nevertheless age is not always properly taken into account.

\section{Materials and methods}

The aim of this retrospective study is to evaluate the usefulness of Barcelona Liver Cancer Clinic (BCLC) in the treatment of HCC, comparing our treatment decision and the BCLC algorithm indications, especially considering elderly patients. In 164 patients affected by HCC treatment the choice was compared with that proposed by BCLC. We performed a univariate analysis considering factors such as sex, age, Child, Okuda, PST and ethiology which influence the decision making process.

\section{Results}

We did not find statistically significative evidence for all the parameters analysed but for age and performance status test (PST) we have had different findings.

In patients submitted to surgery the average age was 63.00 (IQR 56.75-67.75), while patients not surgically treated were of an average age of 68.00 (IQR 60.0073.00). In this case the $\chi^{2}$ showed a significative difference $(p=0.03)$ demonstrating that the younger patients were submitted more easily to surgery when compared with the older group. Analysing PST groups $(0,1,2)$ we

\footnotetext{
* Correspondence: maritrov@hotmail.it

Department of Surgical Sciences, Organ Transplantation and Advanced

Technology University of Catania, Catania
}

found that patients submitted to surgery were belonged to an earlier PST class by contrast with those who underwent other therapies, with a statistically significative $\mathrm{p}$ value $=0.04$.

\section{Conclusions}

Analysing our conduct in treating $\mathrm{HCC}$, we can conclude that our decision making process especially in surgical indication has been influenced by factors regarding the patients, for instance age and PST which require the multidisciplinary $\mathrm{HCC}$ team to pay more attention.

\section{Published: 24 August 2011}

\section{References}

1. Vauthey J-N, Dixon E: Pretreatment assessment of hepatocellular carcinoma: expert consensus statement. HPB 2010, 12:289-299.

2. Llovet JM, Bru C, Bruix J: Prognosis of hepatocellular carcinoma: the BCLC staging classification. Semin Liver Dis 1999, 19:329-338.

3. Grieco A, Pompili M: Prognostic factors for survival in patients with earlyintermediate hepatocellular carcinoma undergoing non-surgical therapy: comparison of Okuda, CLIP, and BCLC staging systems in a single Italian centre. Gut 2005, 54:411-418.

4. Sofia M, La Greca G: Analysis of BCLC treatment indications. Have BCLC modified our choice of treatment in HCC patients? A retrospective study. Hepatogastroenterology 2009, 56:1090-1094.

doi:10.1186/1471-2318-11-S1-A63

Cite this article as: Trovato et al:: Decision making in elderly HCC. BMC Geriatrics 2011 11(Suppl 1):A63

Submit your next manuscript to BioMed Central and take full advantage of:

- Convenient online submission

- Thorough peer review

- No space constraints or color figure charges

- Immediate publication on acceptance

- Inclusion in PubMed, CAS, Scopus and Google Scholar

- Research which is freely available for redistribution

\section{Biomed Central}

